\title{
LAPAROSCOPIC CHOLECYSTECTOMY IN ACUTE CHOLECYSTITIS: OUR EXPERIENCE IN A TEACHING HOSPITAL
}

\author{
P. Deori' ${ }^{1}$ Pranjit Deka ${ }^{2}$
}

${ }^{1}$ Assistant Professor, Department of Surgery, Tezpur Medical College, Assam.

${ }^{2}$ Assistant Professor, Department of Surgery, Tezpur Medical College, Assam.

ABSTRACT
BACKGROUND
Laparoscopic cholecystectomy is considered now the gold standard operative procedure for chronic calculous cholecystitis.
Acute calculous cholecystitis was considered previously as contraindicated for lap. cholecystectomy. But increasing experience and
confidence, laparoscopic cholecystectomy can be extended to acute cholecystitis also with equal efficacy and safety by the experience
surgeon.

\section{OBJECTIVE}

To evaluate the safety and efficacy of lap. cholecystectomy in acute cholecystitis in terms of less pain, less hospital stay, early recovery to full activity and good cosmetic result.

\section{MATERIAL AND METHODS}

This study includes 30 patients with features of acute cholecystitis in a teaching hospital, Assam, India, from Jan. 2014 to Dec. 2015. The preoperative, intraoperative and postop data of all patients were recorded and analysed and compared with other studies.

\section{CONCLUSION}

Lap. cholecystectomy performed in patients with acute cholecystitis within the same admission time is safe procedure with low conversion rate, no mortality and is cost-effective.

\section{KEYWORDS}

Acute Calculous Cholecystitis, Laparoscopic Cholecystectomy.

HOW TO CITE THIS ARTICLE: Deori P, Deka P. Laparoscopic cholecystectomy in acute cholecystitis: our experience in a teaching hospital. J. Evolution Med. Dent. Sci. 2016;5(28):1430-1432, DOI: 10.14260/jemds/2016/336

\section{INTRODUCTION \\ Laparoscopic cholecystectomy has become now gold standard procedure for treating gold stone diseases. The main advantages of laparoscopic cholecystectomy are-less postop pain, less recovery time, short hospital stay, early return to full activity and good cosmetic results. ${ }^{1,2}$ Above all, it maintains the efficacy and safety of surgical gold standard equal to open cholecystectomy. Previously acute cholecystitis was considered to contraindication to lap. cholecystectomy.3,4 Now because of increasing experience and confidence in lap. cholecystectomy, indications of lap. cholecystectomy extended to even in acute cholecystitis. Several studies have documented the safety and feasibility of lap. cholecystectomy for acute cholecystitis by the experienced surgeons.5,6,7,8,9 Our study was designed to analyse and compare the results of lap. cholecystectomy in patients with features of acute cholecystitis.}

\section{MATERIALS AND METHODS}

This study includes 30 patients underwent lap. cholecystectomy for acute calculous cholecystitis in a teaching hospital, Assam, India, from Jan. 2014 to Dec. 2015.

Financial or Other, Competing Interest: None.

Submission 04-03-2016, Peer Review 17-03-2016,

Acceptance 19-03-2016, Published 06-04-2016.

Corresponding Author:

Dr. P. Deori,

Department of Surgery,

Tezpur Medical College, P.O-Bihaguri,

Tezpur, Assam.

E-mail: deoripddr@gmail.com

DOI: 10.14260/jemds/2016/336
The preoperative, intraoperative and postoperative data of all patients were recorded. Other data recorded includesoperative time, duration of hospital stay, conversion to open cholecystectomy and reasons for it, any postop complications. All patients were admitted on emergency basis from routine OPD and emergency dept. The patients were diagnosed as acute calculous cholecystitis on the basis of following criteria.

1. Acute rt. upper abdominal pain.

2. Murphy's sign +ve.

3. Fever.

4. USG findings of acutely inflamed GB with stone with pericholecystic fluid.

\section{Exclusion Criteria}

1. Pts. with no GB stone.

2. Pt. with jaundice, cholangitis,

3. Bil. Pancreatitis, and

4. Pt. with comorbid disease.

It has been long practised even in open cholecystectomy that cholecystectomy is best performed before $72 \mathrm{hrs}$. or within $72 \mathrm{hrs}$. of onset. It is also applicable in lap. chole. In our study, patients were divided into 2 groups- depending upon timing of lap. cholecystectomy performed after onset of acute attack. Gr-1 within 72 hrs. of onset of pain, Gr-2 after 72 hrs. of pain. All patients were given IV fluids, $3^{\text {rd }}$ gen. Cephalosporins antibiotics, Amikacin, IV metronidazole, IV PPI, IM NSAID and were continued for 2 days. Lap. chole were performed by the same surgeon to avoid the operative, complications biasness. All patients underwent standard four port techniques. 


\section{(Fig. of Acute Cholecystitis)}

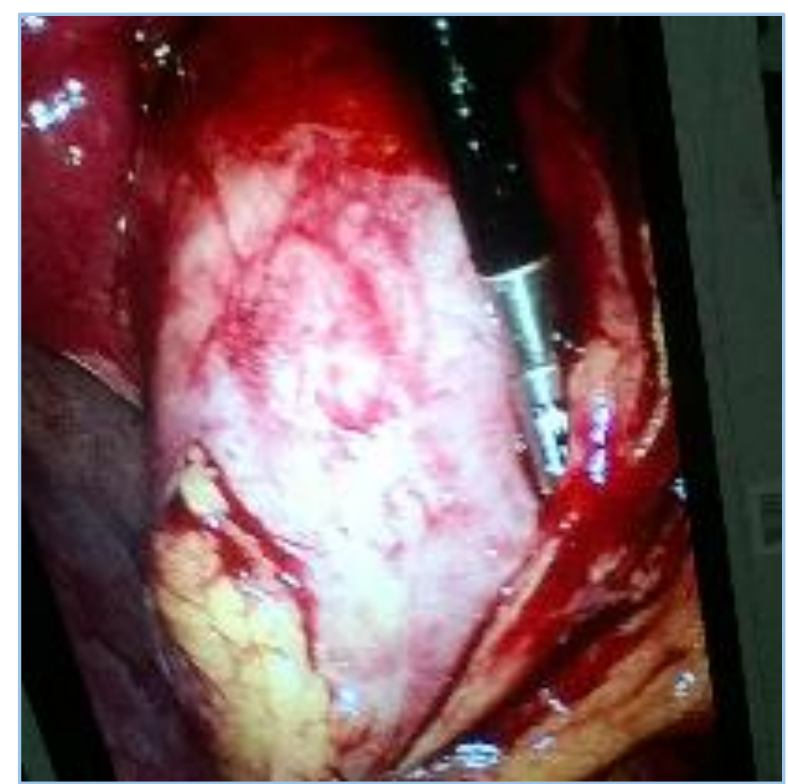

Fig. 1: Acute Cholecystitis Dissecting GB from Liver Bed

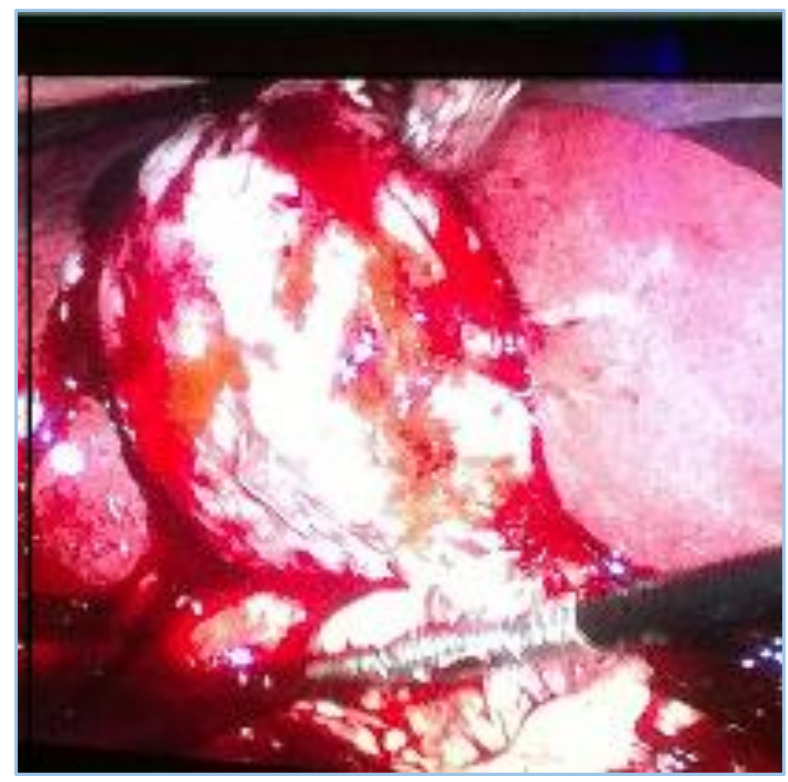

Fig. 2: Acute Cholecystitis Dissecting and finding Cystic Duct \& Artery

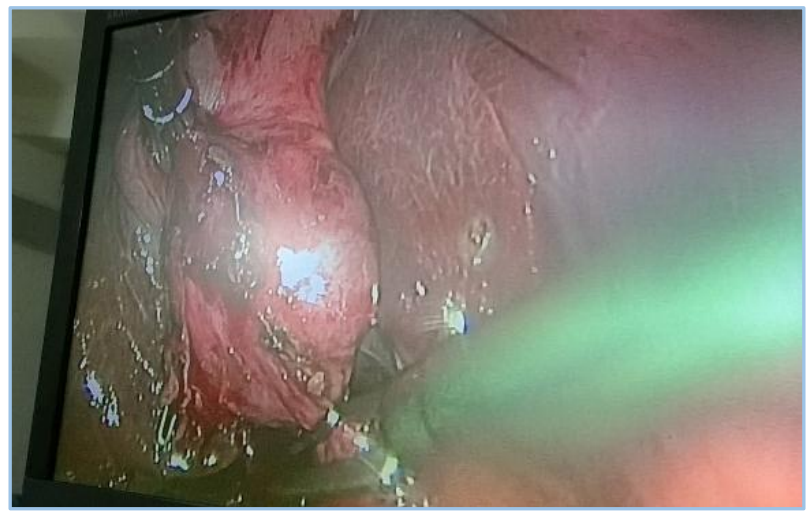

Fig. 3: Acute Cholecystitis

\section{RESULTS}

Of 30 patients undergone lap. chole, female patients were 23 (75\%) and male patients were 7 (25\%). Mean age was 39.6 yrs., ranges from 20 to 60 yrs.; 14 pts. underwent lap. chole within $72 \mathrm{hrs}$. of onset of pain (Gr-1) and 16 pts. were after 72 hrs. (Gr-2) Table-1.

\begin{tabular}{|c|c|c|c|c|}
\hline Gr. & Duration & Total & Male & Female \\
\hline 1. & $<72$ hrs. & $14(46.6 \%)$ & $4(28.5 \%)$ & $10(71.4 \%)$ \\
\hline 2. & $>72$ hrs. & $16(53.3)$ & $3(18.8 \%)$ & $13(81.2 \%)$ \\
\hline \multicolumn{6}{|c|}{ Table 1: Pts. Groups Based on Duration of Symptoms } \\
\hline
\end{tabular}

\begin{tabular}{|c|c|c|}
\hline Characteristics & $\begin{array}{c}\text { Gr-1 LC } \\
\text { within } 72 \\
\text { hrs. }(n=14)\end{array}$ & $\begin{array}{c}\text { Gr-2 LC } \\
\text { after } 72 \text { hrs. } \\
(n=16)\end{array}$ \\
\hline - Pain rt. Hyp, $\mathrm{n}=(\%)$ & $13(92.8 \%)$ & $11(68.7 \%)$ \\
\hline - Murphy's sign, $\mathrm{n}=(\%)$ & $10(71.4 \%)$ & $7(43.7 \%)$ \\
\hline - Fever $>37.5^{\circ} \mathrm{c} \mathrm{n}=(\%)$ & $11(78.5 \%)$ & $9(56.2)$ \\
\hline - USG results n (\%) & & \\
\hline${ }^{*}$ Gall stone & $14(100 \%)$ & $16(100 \%)$ \\
\hline $\begin{array}{c}\text { *Distended GB with } \\
\text { Thickened Wall } \\
\end{array}$ & $12(85.7 \%)$ & $14(87.5 \%)$ \\
\hline $\begin{array}{c}\text { *Pericholecystic } \\
\text { fluid n }(\%)\end{array}$ & $6(42.8 \%)$ & $\$(255 \%)$ \\
\hline
\end{tabular}

\begin{tabular}{|l|c|c|}
\hline Characteristics & $\begin{array}{c}\text { Gr-1 LC } \\
\text { within 72 } \\
\text { hrs. (n=14) }\end{array}$ & $\begin{array}{c}\text { Gr-2 LC after } \\
\mathbf{7 2} \text { hrs. } \\
\text { (n=16) }\end{array}$ \\
\hline - Conversion (n\%) & $0(0 \%)$ & $5(31.2 \%)$ \\
\hline - Operative time (Min) & 91 & 115 \\
\hline - Complications & $1(7.14 \%)$ & $3(18.5 \%)$ \\
\hline - Postop Stay, (Days) & 3 & 4 \\
\hline \multicolumn{2}{|l|}{ Table 3: Results of Lap. Chole for Acute Cholecystitis } \\
\hline
\end{tabular}

From Table 3 the results of Lap. Chole in acute cholecystitis is underlined as follows- Rate of conversion to open chole is high in Gr-2 patients, i.e. 5 (31.2\%) whom Lap. Chole tried after $72 \mathrm{hrs}$. The reasons are -non-visualisation of Calot's triangle in 3 pts., bleeding in 1 patient and difficulties in holding and retracting GB with grasper in 1 patient. Continuous dissection with laparoscopy was continued for 60 mins. The mean operation time excluding conversion was 109.5 mins. as a whole. In Gr-1 it was 91 mins. and in Gr-2 it was 115 mins. (Range from 91 mins. to 122 mins.).

Laparoscopic findings-12 patients had no adhesions around the neck of the GB, 10 patients had mild-to-moderate adhesions, 8 patients had severe adhesions; 24 patients had impacted stone in the infundibulum; 22 patients had distended GB which needed aspiration for facilitating grasping of GB wall. Almost all GB had some amount of wall thickness due to oedema. We retrieved GB through epigastric port with the help of retrieval bag with mild extension of incision in some cases. Big stone needed to be crushed inside the bag with stab knife incision over the GB wall through the opening end of the bag and ovum forceps.

We put sub-hepatic drain irrespective of all the cases for 24 to 48 hrs. There were 4 complications and out of which 3 port site infections, 1 (7.14\%) in Gr-I and 2 (12.5\%) in Gr-II patients; 1 in Gr-II patients developed sub-hepatic abscess. The mean postop stay was 3.16 (Ranges from 2 to 5 days). No mortality and no bile duct injury occurred in this study. 


\section{DISCUSSION}

The traditional and widely practised management of acute cholecystitis during pre-laparoscopic era and even today is initial conservative treatment for symptomatic relief and delayed open or laparoscopic cholecystectomy at 6 to 8 weeks' interval. This traditional approach in open cholecystectomy was however challenged by early cholecystectomy, first advocated by Essenhigh in 19661.10 Since then several randomized studies have shown that early open cholecystectomy is as safe as delayed cholecystectomy with reduced morbidity and hospital stay, lower cost and rapid recovery. ${ }^{10,11}$ provided that necessary expert of the surgeon available.

The lap. chole in acute cholecystitis also appears to be following the same trend as open cholecystectomy. Previously, lap. chole in acute cholecystitis was itself a contraindication because of the fear of increase morbidity due to bile duct injury and high conversion rate. But as time goes on and necessary experience earn by the surgeon many centres has attempted lap. chole in acute cholecystitis. ${ }^{5-9}$ A review of the literature over the last decade shows that early lap. chole in acute cholecystitis is as safe as delayed cholecystectomy. 3,9,12,13 This approach is well supported by a recent international consensus published as Tokyo Guidelines. ${ }^{14}$

In these series, patients were operated with the $\mathrm{H} / \mathrm{O}$ acute attack and on the basis of the pain they were divided into two groups - Gr-1 lap. chole done within $72 \mathrm{hrs}$. of onset of pain and Gr-2 lap. chole done after 72 hrs. of onset of pain. Time required for lap. chole in these series was ranged from 91 mins. to 122 mins. Mean operation time is lengthy in Gr-2 patients -(115 mins.) and in Gr-1 patients it was 91 mins.

The question of relating the time of lap. chole for acute cholecystitis to admission or onset of symptoms has been over emphasised.5,7,11 In our series, it is observed that those who underwent lap. chole within $72 \mathrm{hrs}$. of onset of symptoms ( $\mathrm{Gr}$ 1), there was no complications, no conversion rate; but in $\mathrm{Gr}$ 2 , there were conversion in $4(31.2 \%)$ cases, operative time slightly longer (115 mins.), complication rate $18.5 \%(n=3)$ cases and postop stay is slightly longer (4 days). So based on these series and also from international experience and various data available, we support lap. chole/surgical intervention within $72 \mathrm{hrs}$. of onset of symptoms of acute cholecystitis. It is also observed that because of oedema and inflammation, the dissection is facilitated during this period as per same findings in early open cholecystectomy done for acute cholecystitis.

In this series the overall conversion rate is $31.2 \%$, which is within the reported range from 0 to $39 \% \cdot 6,8,15$ The most common reasons for conversion in our patients in the study were "Unable to identify the structures in Calot's Triangle."

The most common postop complications we found was port site infection in the epigastric port, may be due to infection spread from infected GB tissue and bile leakage to port site during bag retrieval. It was resolved within few days of antibiotics therapy and dressings. In Gr-II, one patient developed subhepatic abscess which resolved after USG guided percutaneous aspiration. No bile duct injury occurred in our series may be due to very low no. of cases.

\section{CONCLUSIONS}

Lap. chole performed in patients with acute cholecystitis within the same admission time is safe procedure with low conversion rate, no mortality and is cost effective.

However, it should be performed as early as possible, preferably within $72 \mathrm{hrs}$. of onset of symptoms, which can be regarded as "Golden Period." If performed within this time it decreases the operation time, conversion rate, morbidity, total hospital stay and of course no mortality.

\section{REFERENCES}

1. Paulino-Netto A. A review of 391 selected open cholecystectomies for comparison with laparoscopic cholecystectomy. Am J Surg 1991;166:71-73.

2. Buanes T, Mjaland O. Complications in laparoscopic and open cholecystectomy: a prospective comparative trial. Surg lap Endo 1996;6(4):266-72.

3. Cuscheiri A, Berci G, Mc Sherry CK. Laparoscopic cholecystectomy. Am J Surg 1990;159(3):273.

4. Schirmer BD, Edge SB, Dix J, et al. Laparoscopic cholecystectomy: treatment of choice for symptomatic cholecystitis. Ann Surg 1991;213(6):665-76.

5. Garber SM, Korman J, Cosgrove JM, et al. Early laparoscopic cholecystectomy for acute cholecystitis. Surg Endosc 1997;11:347-50.

6. Stevens KA, Chi A, Lucas LC, et al. Immediate laparoscopic cholecystectomy for acute cholecystitis: no need to wait. Am J Surg 2006;192(6):756-61.

7. Lo CM, Liu CL, Fan ST, et al. Prospective randomized study of early versus delayed laparoscopic cholecystectomy for acute cholecystitis. Ann Surg 1998;227(4):461-7.

8. Johanson M, Thune A, Blomqvist A, et al. Management of acute cholecystitis in laparoscopic era: results of a prospective, randomized clinical trial. J Gastrointest Surg 2003;7(5):642-5.

9. Papi C, Catarci M, D'Ambrosio L, et al. Timing of cholecystectomy for acute cholecystitis: a meta-analysis. Am J Gastroenterol 2004;99(1):147-55.

10. Essenhigh DM. Management of acute cholecystitis. Br J Surg 1966;53(12):1032-8.

11. Norrby S, Herlin P, Holmin T, et al. Early or delayed cholecystectomy in acute cholecystitis? Aclinical trial. Br J Surg 1983;70(3):163-5.

12. Al-Mulhim, Abdulmohsen A. Timing of early laparoscopic cholecystectomy for acute cholecystitis. Journal of the Society of Laparoendoscopic Surgeons 2008;12:282-7.

13. Sinha R, Sharma N. Acute cholecystitis and laparoscopic cholecystectomy. Journal of the Society of Laparoendroscopic Surgeons 2002;6(1):65-8.

14. Yamashita Y, Takada T, Kawarada Y, et al. Surgical treatment of patients with acute cholecystitistokyo guidelines. J Hepatobiliary Pancreatic Surg 2007;14(1):917.

15. Bhattacharya D, Senapati PSP, Hurle R, et al. Urgent versus interval laparoscopic cholecystectomy for acute cholecystitis study. J Hepatobiliary Pancreat Surg 2002;9(5):538-42. 